\title{
TAXONOMIC CONTRIBUTION TO THE KNOWLEDGE OF THE ORIBATID MITE GENUS NEORIBATES (ACARI, ORIBATIDA, PARAKALUMMIDAE)
}

\author{
Sergey G. Ermilov ${ }^{1 *}$ and Josef Starý ${ }^{2}$
}

\author{
${ }^{1} \mathrm{X}-\mathrm{BIO}$ Institute, Tyumen State University, Tyumen, Russia \\ ${ }^{2}$ Biology Centre v.v.i., Czech Academy of Sciences, Institute of Soil Biology, České Budějovice, \\ Czech Republic \\ *corresponding author; e-mail: ermilovacari@yandex.ru
}

ABSTRACT: A new oribatid mite species of the genus Neoribates (Oribatida Parakalummidae) is described from Bolivia. A new generic diagnosis and an identification key to the known species of the aforementioned genus from the Neotropical region are provided.

KEY WORDS: Parakalummid mites, taxonomy, morphology, identification key, tropics.

DOI: 10.21684/0132-8077-2021-29-1-3-9

\section{INTRODUCTION}

This work is based on the material received from the collection of the Institute of Soil Biology, České Budějovice, the Czech Republic. It is part of our continuing study of oribatid mites (Acari, Oribatida) of Bolivia (e.g., Ermilov and Niedbała 2013). During the taxonomic identification of Parakalummidae, we found one new species belonging to the genus Neoribates Berlese, 1914 (nominative subgenus). The main goal of the paper is to describe and illustrate this new species.

Neoribates was proposed by Berlese (1914), with Oribata roubali Berlese, 1910 as a type species. Currently, the genus comprises four subgenera and 66 species: N. (Neoribates) Berlese, 1914-55 species; N. (Parakalumma) Jacot, 1929-five species; N. (Perezinigokalumma) Subías, 2004-four species; and N. (Pseudoneoribates) Ermilov and Corpuz-Raros, 2015 - two species. Collectively, the above species have a cosmopolitan distribution, except for the Antarctic region (Subías 2021).

An additional goal of the paper is to revise the generic diagnosis of Neoribates and to update (after Ermilov and Kalúz 2013) an identification key to the known species from the Neotropical region.

\section{MATERIALS AND METHODS}

Specimens. The specimens of the new species were kindly provided by the Institute of Soil Biology, České Budějovice, Czech Republic (the collection locality is provided in the Material examined section). The type material has been deposited in two institutions: the Senckenberg Museum of Natural History, Görlitz, Germany (SMNH); and the Tyumen State University Museum of Zoology, Tyumen, Russia (TSUMZ).
Observation and documentation. Specimens were mounted in lactic acid on temporary cavity slides for measurement and illustration. Body length was measured in lateral view, from the tip of the rostrum to the posterior edge of the notogaster. Notogastral width refers to the maximum width of the notogaster in dorsal view (behind pteromorph). Lengths of body setae were measured in lateral aspect. All body measurements are presented in micrometers $(\mu \mathrm{m})$. Formulas for leg setation are given in parentheses according to the sequence trochanter-femur-genu-tibia-tarsus (famulus included). Formulas for leg solenidia are given in square brackets according to the sequence genu-tibia-tarsus. Drawings were made with a camera lucida using a Leica transmission light microscope "Leica DM 2500".

Terminology. Morphological terminology used in this paper follows that of Grandjean: see Travé and Vachon (1975) for references, Norton (1977) for leg setal nomenclature and Norton and BehanPelletier (2009) for overview.

Abbreviations. Prodorsum: $r r$ - rostral ridge; lam —lamella; slam — sublamella; $\mathrm{Al}$ — sublamellar porose area; $l r, p r$ - lateral and posterior prodorsal ridge, respectively; ro, le, in, $b s$-rostral, lamellar, interlamellar, and bothridial setae, respectively; $A d$ - dorsosejugal porose area; $D$ - dorsophragma; $P$-pleurophragma. Notogaster: $c, l a, l m, l p, h$, $p$-notogastral setal alveoli; $S a, S 1, S 2, S 3$-notogastral sacculi; $i a, i m$, ip, ih, ips-lyrifissures; gla - opisthonotal gland opening. Gnathosoma: $a$, $m, h$-subcapitular setae. Epimeral and lateral podosomal regions: $1 a, 1 b, 1 c, 2 a, 3 a, 3 b, 3 c, 4 a$, $4 b, 4 c$ - epimeral setae; $P d I, P d I I$ - pedotecta I, II, 
respectively; dis-discidium; $c p c$ - circumpedal carina; dep - depression. Anogenital region: $g, a g$, an, ad - genital, aggenital, anal, and adanal setae, respectively; iad - adanal lyrifissure; $p o$ - preanal organ. Legs: $\mathrm{Tr}, \mathrm{Fe}, \mathrm{Ge}, \mathrm{Ti}, \mathrm{Ta}$-leg trochanter, femur, genu, tibia, and tarsus, respectively; $\omega, \varphi$, $\sigma$-leg solenidia; $\varepsilon$ - leg famulus; $d, l, v, b v, e v, f t$, $t c, i t, p, u, a, s, p v, p l$-leg setae; $p a$ - porose area.

\section{GENERIC DIAGNOSIS OF NEORIBATES}

Adult. Body size: Medium to large (length about 290-950). Integument: Smooth, rarely partially striate or foveolate. Prodorsum: Rostrum rounded or pointed. Lamella of medium length, directed anteriorly from bothridium as broad plate (subgenus Perezinigokalumma) or narrow carina, without cusp and tooth distally. Translamella present or absent. Sublamella and sublamellar porose area present. Prolamella present, curving backwards mediodistally (subgenus Pseudoneoribates) or absent. Posterior prodorsal ridge (tutorium) usually present. Rostral, lamellar and interlamellar setae well developed, rarely in reduced. Bothridial seta setiform or with developed head. Bothridium cup-shaped. Exobothridial seta usually absent. Notogaster: Anterior margin of notogaster distinct, convex or straight medially. Dorsosejugal porose area present. Pteromorph auriculate, sometimes pointed in anterior part (subgenus Parakalumma). Octotaxic system represented by sacculi. With 10 pairs of short, setiform notogastral setae or their alveoli; seta $c$ positioned on notogaster. Posterior notogastral tectum absent. Gnathosoma: Subcapitulum diarthric. Palp with setation 0-2-1-3$9(+\omega)$. Solenidion of palptarsus arch-like, connected to eupathidium. Axillary saccule absent. Chelicera chelate-dentate. Epimeral and lateral podosomal regions: Epimeral region with setation 3-1-3-3. Humeral porose areas not observed. Pedotecta I, II, circumpedal carina and discidium present. Anogenital region: Four or five pairs of genital, one pair of aggenital, two pairs of anal and three pairs of adanal setae. Adanal lyrifissure located close and lateral to anal plate. Marginal porose area present or absent. Legs: All legs mono-, bi- or heterotridactylous. Porose area present on all tarsi, tibiae and femora, and on trochanters III, IV. Sexual dimorphism: present (in structure of posterior part of notogaster) or absent.

Remarks. An identification key to known subgenera of Neoribates, including subgeneric differences, presented by Ermilov and CorpuzRaros (2015).

\section{DESCRIPTION OF NEW SPECIES}

\section{Neoribates (Neoribates) boliviensis Ermilov and Starý, sp.n.}

Figs. 1-9

Diagnosis Body size: 680-796 × 464-531. Body surface without heavy sculpturing and ornamentation. Rostrum rounded, with longitudinal rostral ridge. Prodorsal setae long: rostral and lamellar setae setiform, barbed; interlamellar seta flagellate, roughened; bothridial seta setiform, roughened, directed posteriad. Anterior notogastral margin convex and rounded medially. All notogastral setae represented by alveoli. Epimeral setae $1 a$, $2 a$ and $3 a$ thickened, heavily barbed; others thin, slightly barbed. Pedotectum II with strong posterolateral tooth. Four pairs of genital setae. Anogenital setae thin, setiform, roughened; $a d_{1}$ and $a d_{2}$ longest; $a d_{3}$ close and anterolateral to anal aperture. Adanal lyrifissure slightly diagonal to anal plate. Marginoventral porose area represented by numerous parts. All legs with three claws.

Description. Measurements. Body length: 796 (holotype: female), 680, 697 (two paratype males), 796 (one paratype female); notogaster width: 514 (holotype), 464, 481 (two paratype females), 531 (one paratype female).

Integument. Body color dark brown. Body surface microporose, visible under high magnification $(\times 1,000)$ in dissected specimen. Lateral parts (between bothridia and acetabula I-IV) partially microgranulate.

Prodorsum (Figs. 1, 3). Rostrum rounded, with short longitudinal rostral ridge, creating illusion of a pointed rostrum in dorsal view. Lamella located dorsolaterally, longer than half of prodorsum, curving anteromedially to insertion of lamellar seta. Translamella absent. Sublamella is half the length of the lamella. Sublamellar porose areas oval $(24 \times$ 16), partially covered by sublamella. Rostral (77-82) and lamellar (86-94) setae setiform, barbed. Interlamellar seta (131-135) flagellate, roughened. Exobothridial seta not observed. Bothridial seta (131-135) setiform, roughened, directed posteriad. Sejugal porose area diffuse, transversely oriented. Anterior ridge absent; lateral and posterior ridges simple.

Notogaster (Figs. 1, 3, 4). Anterior notogastral margin distinctly convex and rounded medially. Ten pairs of notogastral setae represented by alveoli. Four pairs of sacculi with small opening and slightly elongate channel. Opisthonotal gland opening and all lyrifissures well visible. 


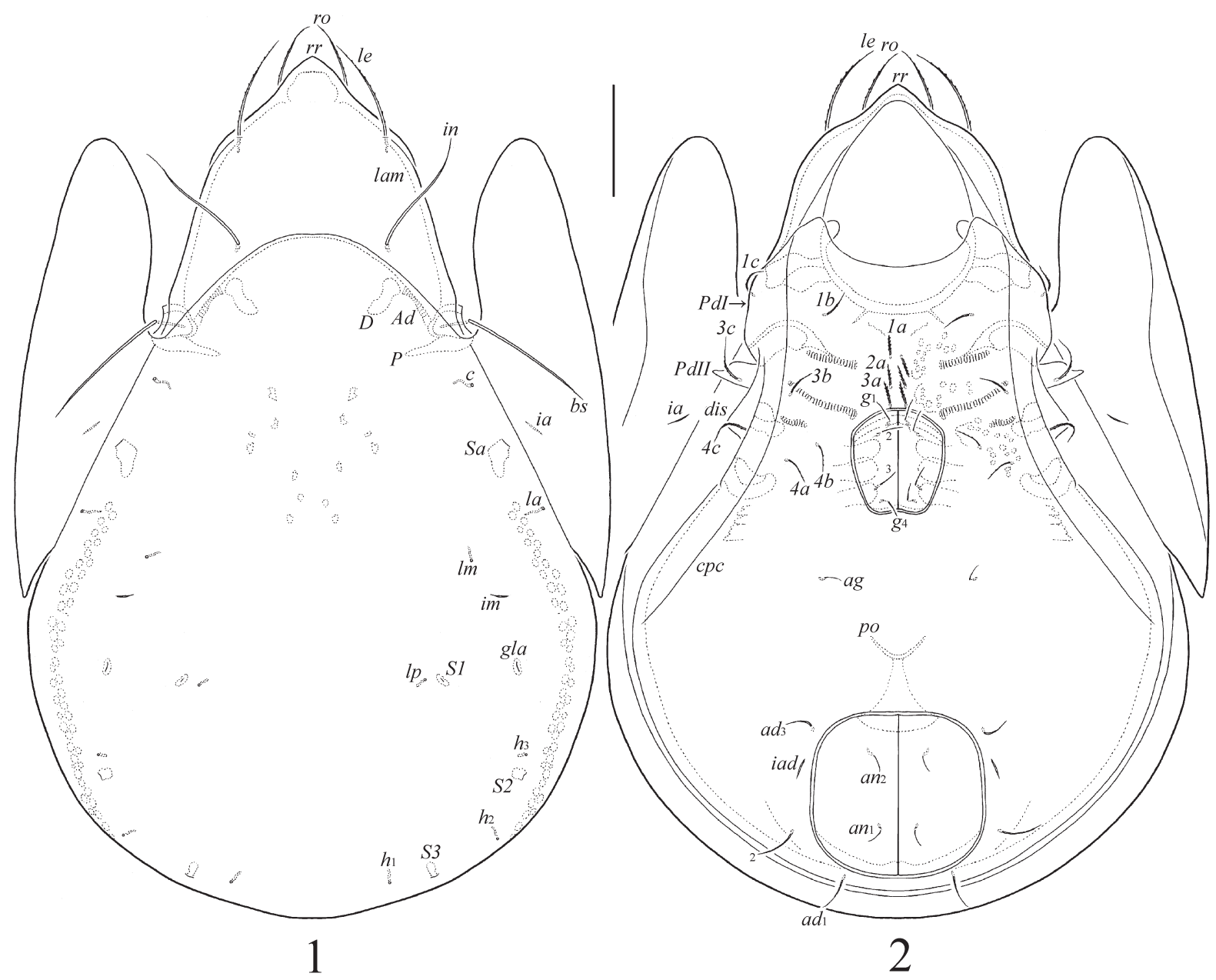

Figs. 1-2. Neoribates boliviensis sp.n., adult: 1-dorsal view; 2-ventral view (not shown: gnathosoma and legs). Scale bar $=100 \mu \mathrm{m}$.

Gnathosoma (Fig. 5). Typical for Neoribates (e.g., Ermilov 2019). Subcapitulum longer than wide: $155-164 \times 123-131$. Subcapitular setae $a$ (32-36) and $h(45-49)$ setiform, barbed; seta $m$ (28) setiform, thin, slightly barbed. Adoral seta (24) setiform, heavily barbed. Palp (length: 118-123) with typical setation: $0-2-1-3-9(+\omega)$. Postpalpal setae (8) spiniform, smooth. Chelicera (length: 168-172) with two setiform, barbed setae (cha: 53-57) longer than (chb: 32-36).

Epimeral and lateral podosomal regions (Figs. 2, 3). Epimeral setal formula: 3-1-3-3. Setae $1 a$, $2 a$ and $3 a$ (32-36) thickened, pointed apically, heavily barbed; others $(3 c, 4 c: 53-57 ; 1 b, 1 c, 3 b$, $4 a, 4 b$ : 32-36) setiform, thin, slightly barbed. Pedotectum II with strong posterolateral tooth. Discidium triangular, rounded distally. Circumpedal carina long, reaching anterior margin of ventral plate.

Anogenital region (Figs. 2-4). Four pairs of genital (18-20), one pair of aggenital (18-20), two pairs of anal (18-20) and three pairs of adanal $\left(a d_{1}\right.$, $\left.a d_{2}: 36 ; a d_{3}: 24-28\right)$ setae setiform, roughened. Adanal seta $a d_{1}$ posterior, $a d_{2}$ posterolateral and $a d_{3}$ anterolateral to anal aperture. Adanal lyrifissure located close and slightly diagonal to anal plate and posterior to $a d_{3}$. Marginoventral porose area represented by numerous rounded and oval parts. Ovipositor elongate $(249 \times 45)$, blade $(118)$ shorter than length of distal section (beyond middle fold; 131). Each of three blades with four smooth setae; $\psi_{1} \approx \tau_{1}(57)$ setiform, $\psi_{2} \approx \tau_{\mathrm{a}} \approx \tau_{\mathrm{b}} \approx \tau_{\mathrm{c}}$ (24) elongate thorn-like. Six coronal setae minute (4).

Legs (Figs. 6-9). Tridactylous, median claw thicker than lateral claws, all barbed on dorsal side. Lateral claws with minute tooth ventrodistally. Dorsoparaxial porose areas on femora I-IV and on trochanters III, IV well visible; proximoventral porose area on tarsi I-IV and distoventral porose area on tibiae I-IV slightly observed. Formulas of leg setation and solenidia: I (1-5-3-4-20) [1-2-2], II (1-5-3-4-15) [1-1-2], III (2-3-1-3-15) [1-1- 


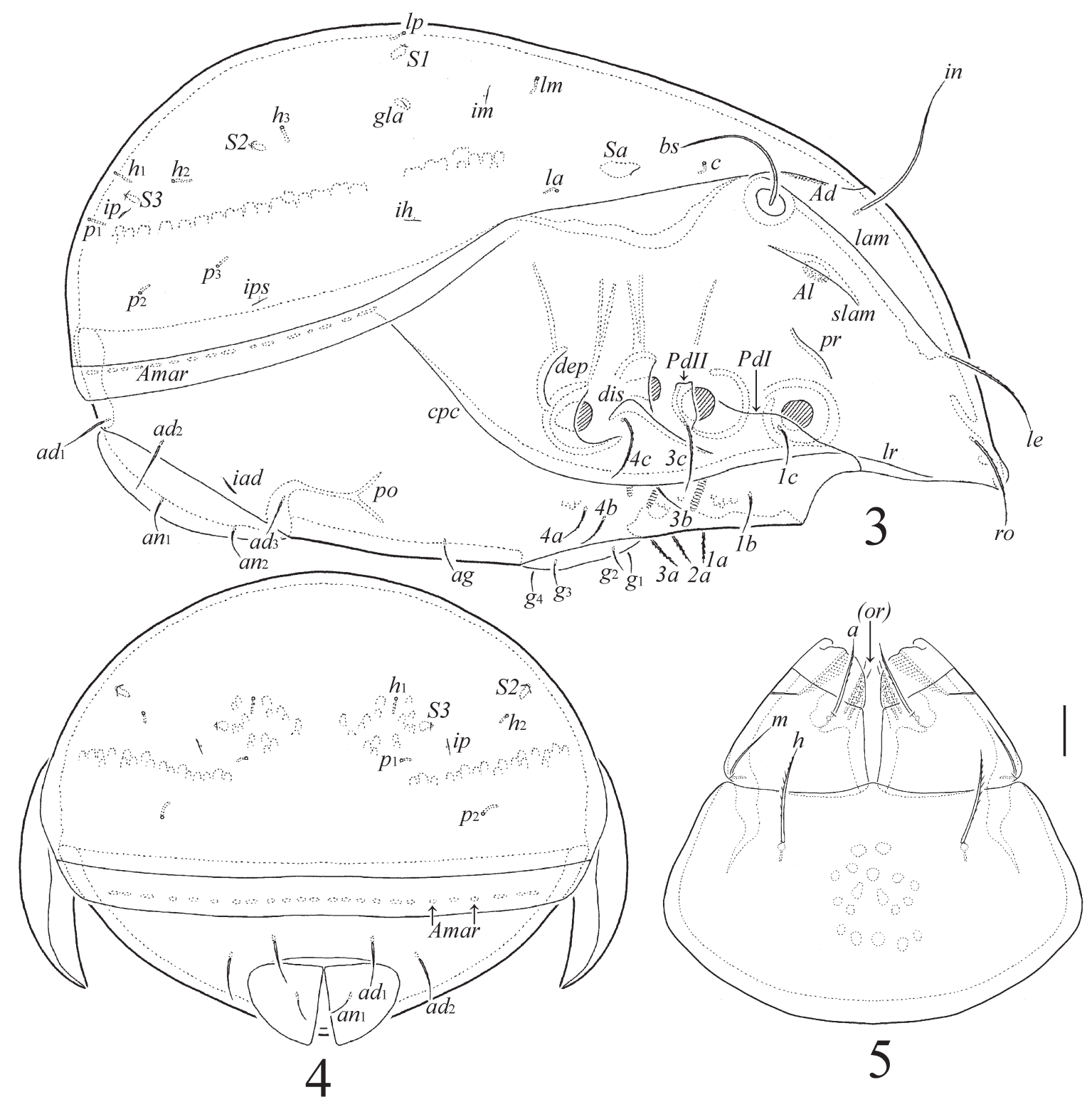

Figs. 3-5. Neoribates boliviensis sp.n., adult: 3-lateral view (not shown: pteromorph, gnathosoma and legs); 4posterior view; 5-subcapitulum, dissected, ventral view. Scale bars $=100 \mu \mathrm{m}(3,4), 20 \mu \mathrm{m}(5)$.

0], IV (1-2-2-4-12) [0-0-0]; homology of setae and solenidia indicated in Table 1 . Solenidia $\omega_{1}$ on tarsus I, $\omega_{1}$ and $\omega_{2}$ on tarsus II and $\sigma$ on genua II and III thickened, rounded apically; other solenidia longer, setiform. Famulus short, straight, swollen distally, inserted between solenidion $\omega_{2}$ and seta $f t$ ". Setae $l$ " on genu I thick.

Material examined. Holotype (female) and three paratypes (two males and one female): Bolivia, Espejillos environs, near Amboró National Park, $17^{\circ} 53^{\prime} 22^{\prime \prime}$ S, $63^{\circ} 26^{\prime} 48^{\prime \prime} \mathrm{W}, 562 \mathrm{~m}$ a.s.1., sifting rainforest leaf litter, November 29, 2009 (collected by B. Greenway).

Type deposition. The holotype is deposited in the collection of the SMNH; three paratypes are deposited in the collection of the TSUMZ. All specimens are preserved in $70 \%$ solution of ethanol with a drop of glycerol.

Etymology. The specific name boliviensis refers to the country of origin, Bolivia.

Remarks. Neoribates boliviensis sp.n. is morphologically most similar to Neoribates setiger Balogh and Mahunka, 1978 from Australia (Balogh and Mahunka 1978) in general traits (bothridial seta setiform; all prodorsal setae long; four pairs of genital setae; adanal setae $a d_{1}$ and $a d_{2}$ comparatively long). However, the new species differs from the latter in larger body size $(680-796 \times 464-531$ vs. $559-583 \times 389-450)$, the presence of a median ridge on the rostrum ( $v s$. 


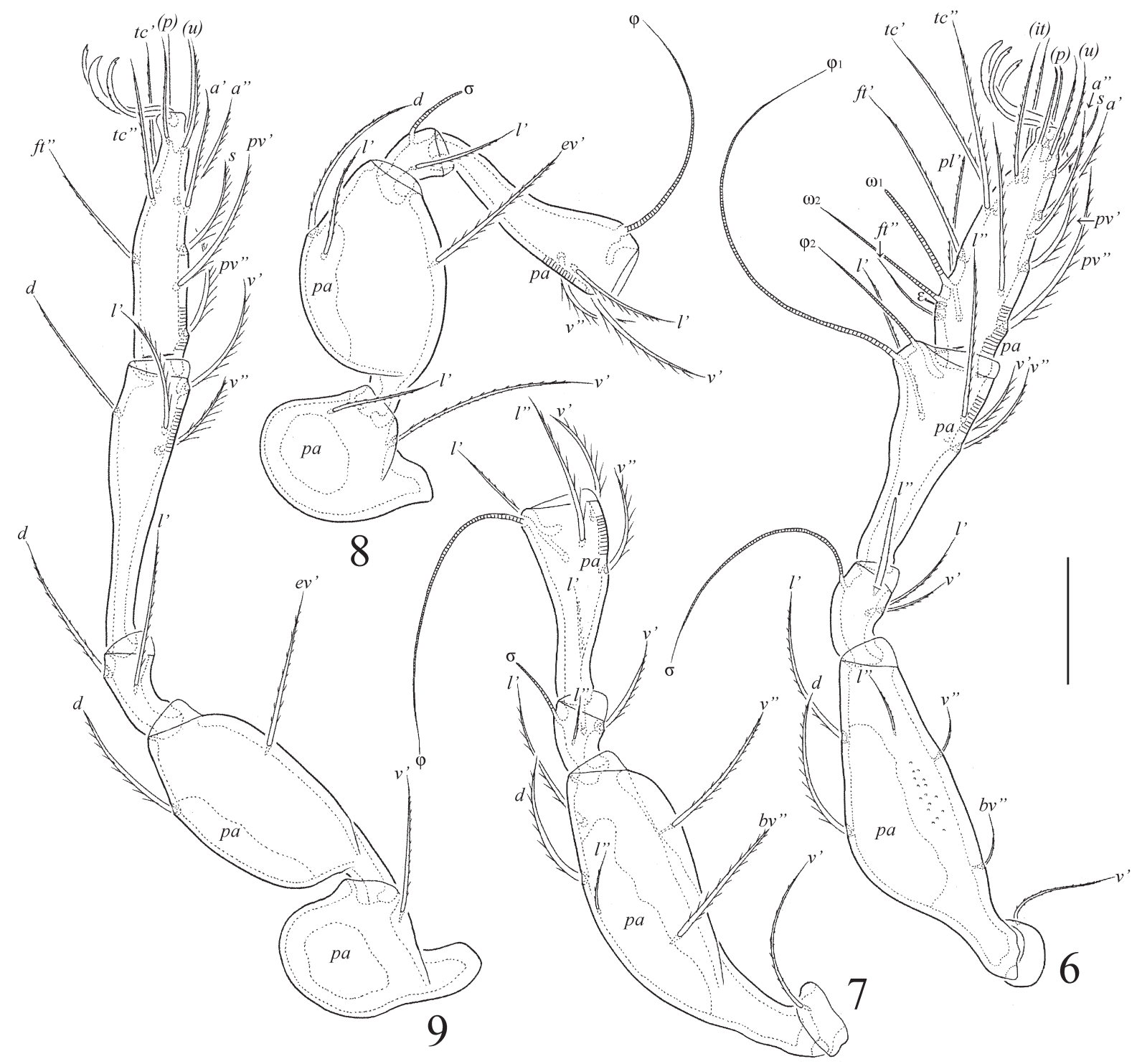

Figs. 6-9. Neoribates boliviensis sp.n., adult: 6-leg I, right, antiaxial view; 7-leg II, without tarsus, right, antiaxial view; 8-leg III, without tarsus, left, antiaxial view; 9-leg IV, left, antiaxial view. Scale bar=50 $\mu \mathrm{m}$.

ridge absent), rounded ( $v s$. truncate) anterior margin of the notogaster, flagellate and roughened (vs. setiform, heavily barbed) interlamellar seta, and roughened (vs. heavily barbed) bothridial seta.

\section{KEY TO KNOWN SPECIES OF NEORIBATES FROM THE NEOTROPICAL REGION}

1. Lamella represented by broad plate.... .2 (subgenus Perezinigokalumma Subías, 2004) - Lamella represented by narrow ridge 2. Notogaster and anogenital region striate; sexual dimorphism absent in structure of posterior part of notogaster; body size: 300-330 × 170-195 nigokalumma) munizi (Balogh and Mahunka, 1974) (see Balogh and Mahunka 1974). Distribution: Cuba. - Notogaster and anogenital region not striate; sexual dimorphism present in structure of posterior part of notogaster (male with caudal protruding)...3 3. Head of bothridial seta oval; lamella with slight indentation and lateral spine anteriorly in female; lamellar seta of medium length, distinctly longer than rostral seta in female; body size: $291-376 \times$ 160-211 Neoribates (Perezinigokalumma) piton (Mahunka, 1998) (see Mahunka 1998). Distribution: Antilles.

- Head of bothridial seta narrowly elongate, oval; lamella rounded anteriorly in female; lamellar seta short, similar to rostral seta in length in female; body size: $314-345 \times 166-191$... Neoribates (Perezinigo- 
kalumma) foveolata (Balogh and Mahunka, 1969) (see Balogh and Mahunka 1969). Distribution: Neotropical region.

4. Pteromorph pointed in anterior part.

(subgenus Parakalumma Jacot, 1929);

Neoribates (Parakalumma) robustus (Banks, 1895) with two similar subspecies: Neoribates (Parakalumma) robustus robustus (Banks, 1895) (see Banks 1895; Berlese 1914; Jacot 1929; Aoki 1984; body size: 725-930 × 520-730; distribution: western USA, Japan.) and Neoribates (Parakalumma) robustus floridanus (Jacot, 1935) (see Jacot 1935; body size: 780-920 × 586-696; distribution: USA, Florida).

- Pteromorph rounded in anterior part. .5 (subgenus Neoribates Berlese, 1915).

5. Bothridial seta setiform; body size: $680-796 \times$ 464-531 ... Neoribates (Neoribates) boliviensis sp.n. Distribution: Bolivia.

- Bothridial seta with developed head ............... 6

6. Head of bothridial seta of medium length, about one third the length of stalk

... 7

- Head of bothridial seta short, about one fifth to one eighth the length of stalk ............................. 9

7. Rostrum with median longitudinal ridge; anterior notogastral margin straight; body size: 481-564× 332-398

..Neoribates (Neoribates) peruensis Ermilov, 2016 (see Ermilov et al. 2016). Distribution: Neotropical region.

- Rostrum without median longitudinal ridge; anterior notogastral margin distinctly convex..... 8 8. Head of bothridial seta lanceolate, narrowly elongate, smooth; adanal setae $a d_{1}$ and $a d_{2}$ short; body size: $670 \times 525$

..... Neoribates (Neoribates) fulvus Sellnick, 1923 (see Sellnick 1923). Distribution: Neotropical region. - Head of bothridial seta clavate of slightly dilated unilaterally, barbed; adanal setae $a d_{1}$ and $a d_{2}$ long; body size: $450-480 \times 380$

..Neoribates (Neoribates) depressus (Banks, 1895) (see Banks 1895; Jacot 1933). Distribution: Nearctic region, USA (Florida).

9. Rostral and lamellar setae thickened, erect; head of bothridial seta fusiform; body size: $363-382 \times$ 270-294 Neoribates

(Neoribates) erectus Balogh and Mahunka, 1969 (see Balogh and Mahunka 1969). Distribution: Brazil.

- Rostral and lamellar setae setiform, not erect; head of bothridial seta lanceolate; body size: 805-820 × 630-640 ...................................... Neoribates (Neoribates) formaminiferus Sellnick, 1923 (see Sellnick 1923). Distribution: Brazil.

\section{ACKNOWLEDGEMENTS}

The authors would like to thank coleopterologist Dr. B. Greenway (London, UK) for collecting soil samples in Bolivia.

\section{REFERENCES}

Aoki, J. 1984. New and unrecorded oribatid mites from Amami-Ohshima island, southwest Japan. Zoological Science, 1: 132-147.

Balogh, J. and Mahunka, S. 1969. The zoological results of the Hungarian soil zoological expeditions to South America. 11. Acari: oribatids from the material of the second expedition, II. Opuscula Zoologica Budapest, 9(1): 31-69.

Balogh, J. and Mahunka, S. 1974. A foundation of the oribatid (Acari) fauna of Cuba. Acta Zoologica Academiae Scientiarum Hungaricae, 20(1-2): 1-25.

Balogh, J. and Mahunka, S. 1978. Data to the Oribatid fauna of Australia (Acari), I. Opuscula Zoologica Budapest, 15(1-2): 31-49.

Banks, N. 1895. On the Oribatoidea of the United States. Transactions of the American Entomological Society, 22: 1-16.

Berlese, A. 1914. Acari nuovi. Manipulus IX. Redia, 10(1): 113-150.

Ermilov, S.G. 2019. On oribatid mites with auriculate pteromorphs in Taiwan (Acari, Oribatida). Zoologichesky Zhurnal, 98(7): 758-772.

Ermilov, S.G. and Corpuz-Raros, L. 2015. A new subgenus and two new species of oribatid mites of the genus Neoribates (Acari, Oribatida, Parakalummidae) from the Philippines. Zootaxa, 3956(2): 224-238.

Ermilov, S.G. and Kalúz, S. 2013. Two new species of Neoribates (Neoribates) (Acari, Oribatida, Parakalummidae) from India. International Journal of Acarology, 39(5): 408-413.

Ermilov, S.G. and Niedbała, W. 2013. Contribution to the knowledge of the oribatid mite fauna of Bolivia, Zambia, Cambodia and Vietnam, with descriptions of two new species (Acari, Oribatida). Spixiana, 36(1): 9-19.

Ermilov, S. G., Friedrich, S. and Kalúz, S. 2016. A new species of Neoribates (Neoribates) (Acari: Oribatida: Parakalummidae) with key to the Neotropical species of the subgenus. Biologia, 71 (6): 673-677.

Jacot, A.P. 1929. American oribatid mites of the subfamily Galumninae. Bulletin of the Museum of Comparative Zoölogy at Harvard College, 69(1): 3-36.

Jacot, A.P. 1933. The primitive Galumninae (Oribatoidea-Acarina) of the Middle West. American Midland Naturalist, 14(6): 680-703.

Jacot, A.P. 1935. The large-winged mites of Florida. The Florida Entomologist, 19(1): 1-14. 
Mahunka, S. 1998. New data on oribatids (Acari: Oribatida) from St. Lucia (Antilles). Acarologica Genevensia LXXXIX. Revue suisse de Zoologie, 105(4): 839-877.

Norton, R.A. 1977. A review of F. Grandjean's system of leg chaetotaxy in the Oribatei (Acari) and its application to the family Damaeidae. In: D.L. Dindal (Ed.). Biology of Oribatid Mites. SUNY College of Environmental Science and Forestry, Syracuse, pp. 33-61.

Norton, R.A. and Behan-Pelletier, V.M. 2009. Oribatida. In: G.W. Krantz and D.E. Walter (Eds.).
A Manual of Acarology. Texas University Press, Lubbock (TX), ch. 15, pp. 430-564.

Sellnick, M. 1923. Oribatideos Brasilieros, I. Galumnae. Archivos do Museu Nacional, 24: 303-320.

Subías, L.S. 2021. Listado sistemático, sinonímico y biogeográfico de los Ácaros Oribátidos (Acariformes: Oribatida) del mundo (excepto fósiles), $16^{\mathrm{a}}$ actualización. $532 \mathrm{pp}$. bba.bioucm.es/cont/ docs/RO_1.pdf

Travé, J. and Vachon, M. 1975. François Grandjean. 1882-1975 (Notice biographique et bibliographique). Acarologia, 17(1): 1-19.

Table 1

Leg setation and solenidia of Neoribates boliviensis sp.n.

\begin{tabular}{|l|l|l|l|l|l|}
\hline Leg & $\operatorname{Tr}$ & $\mathrm{Fe}$ & $\mathrm{Ge}$ & $\mathrm{Ti}$ & $\mathrm{Ta}$ \\
\hline $\mathrm{I}$ & $v^{\prime}$ & $d,(l), b v^{\prime}, v^{\prime \prime}$ & $(l), v^{\prime}, \sigma$ & $(l),(v), \varphi_{1}, \varphi_{2}$ & $(f t),(t c),(i t),(p),(u),(a), s,(p v), v^{\prime},(p l), l^{\prime}, \varepsilon, \omega_{1}, \omega_{2}$ \\
\hline II & $v^{\prime}$ & $d,(l), b v^{\prime}, v^{\prime \prime}$ & $(l), v^{\prime}, \sigma$ & $(l),(v), \varphi$ & $(f t),(t c),(i t),(p),(u),(a), s,(p v), \omega_{1}, \omega_{2}$ \\
\hline III & $l^{\prime}, v^{\prime}$ & $d, l^{\prime}, e v^{\prime}$ & $l^{\prime}, \sigma$ & $l^{\prime},(v), \varphi$ & $(f t),(t c),(i t),(p),(u),(a), s,(p v)$ \\
\hline IV & $v^{\prime}$ & $d, e v^{\prime}$ & $d, l^{\prime}$ & $d, l^{\prime},(v)$ & $f t^{\prime},(t c),(p),(u),(a), s,(p v)$ \\
\hline
\end{tabular}

Note: Roman letters refer to normal setae, Greek letters to solenidia (except $\varepsilon$-famulus), Single quotation mark (') designates setae on the anterior and double quotation mark (") - setae on the posterior side of a given leg segment. Parentheses refer to a pair of setae. 